\title{
Analysis of patient and nurse preferences for self-administered FSH injection devices in select European markets
}

This article was published in the following Dove Press journal: International Journal of Women's Health

\author{
Pierre Zitoun' \\ Jaya Parikh² \\ Martine $\mathrm{Nijs}^{3}$ \\ Wenjie Zhang ${ }^{4}$ \\ Rachel Levy-Toledano ${ }^{5}$ \\ Boxiong Tang ${ }^{6}$
}

'American Hospital of Paris, Neuillysur-Seine, France; ${ }^{2}$ Lister Fertility Clinic, London, UK; ${ }^{3} \mathrm{Nij}$ Geertgen, Elsendorp, the Netherlands; ${ }^{4}$ WG Group, New York, NY, USA; ${ }^{5}$ Theramex HQ UK Limited, London, UK; ${ }^{6}$ Teva Pharmaceuticals, Frazer, PA, USA
Correspondence: Boxiong Tang Growth Markets/GHEOR, Teva Pharmaceuticals, 4I Moores Road, Frazer, PA 19355, USA

Tel + I $610786732 \mid$

Fax + I 6107276150

Email boxtang@yahoo.com
Purpose: The purpose of this study was to assess product-specific features for a variety of self-administered injection devices and identify key factors that patients and nurses in select European markets find most important when selecting injection devices for self-administration of recombinant human follicle-stimulating hormone and urinary human follicle-stimulating hormone for fertility/reproductive therapy.

Patients and methods: Patients $(\mathrm{N}=402)$ in France, Italy, Spain, Germany, the UK, the Netherlands, and Belgium, as well as reproductive/fertility nurses $(\mathrm{N}=40)$ in Germany, Italy, France, Spain, and the Czech Republic were surveyed. All patients were previously prescribed a follicle-stimulating hormone (FSH) treatment for either in vitro fertilization or ovulation induction. Patient and nurse preferences for attributes across all injection devices in the market were obtained via an online questionnaire and evaluated using the maximum differential scaling (MaxDiff) and conjoint analyses, which captured the relative importance of the selected FSH injection device attributes to determine specific qualities in overall product preference.

Results: Both the MaxDiff and conjoint analyses indicated that, for patients and nurses, the ideal FSH injection device would be a highly accurate, multi-use reusable pen injector with a dial-back function that would be easy for both use and education/instruction. Patients and nurses each selected attributes pertinent to their own experiences with the FSH injection device. Categorically, patients valued factors that resulted in minimal impact on daily life, including reduced injection volume to minimize injection-site pain, as well as a reusable device that would be easy to use; nurses placed greater value on a device that would be easy to teach in order to instruct the greatest number of patients while minimizing risk

Conclusion: Patient and nurse preferences were aligned on certain selected attributes of the FSH products. Although this study was an unbranded examination of attributes across all injection devices currently in the market, results demonstrated that the preferred product attributes were all characteristics of the Ovaleap ${ }^{\circledR}$ Pen.

Keywords: infertility, prefilled pen device, recombinant human follicle-stimulating hormone, urinary follicle-stimulating hormone, preference

\section{Introduction}

Fertility rates in Europe are among the lowest worldwide, with an average of 1.5 children per woman. ${ }^{1}$ This low fertility rate can be largely attributed to the current cultural shifts, where women are deciding to have children later in life, which can lead to significant difficulties in conception. As such, the use of in vitro fertilization (IVF) and other treatment-based fertilization techniques has continued to rise in Europe in recent years. During IVF and intracytoplasmic sperm injection procedures, subcutaneous 
injection of medications is used for ovarian stimulation in order to trigger the production and development of multiple eggs, thereby increasing the chances of conception. Although there are a growing number of infertile individuals using IVF or intracytoplasmic sperm injection to conceive, discontinuation is always a central issue surrounding fertility treatment. A number of factors such as psychological burden, physical challenge, depersonalized care, and complex injection protocol tend to impair treatment adherence..$^{2-4}$ Efficacy (pregnancy rate), tolerability (reaction to injection pain), and convenience (dosing accuracy, ease of use, and number of injections) have been the primary points of concern for patients when choosing self-administered injection devices for IVF treatment. ${ }^{5-11}$

In a prospective, observational study that evaluated 5,328 patients across 43 German IVF centers over a period of 1.75 years, Welcker et al found the use of pen devices to be less painful, less stressful, and easier and more convenient, and their use was associated with greater patient satisfaction. ${ }^{7}$ In a market research study of a redesigned follitropin alfa pen injector for infertility, Abbotts et al argued that a key attribute of any injection device is the number of steps required to prepare and administer the injection; fewer, easier steps are likely to reduce injection errors and contribute to patient confidence. $^{8}$

In recent years, injection devices for self-administration of recombinant human follicle-stimulating hormone (r-hFSH) and urinary human follicle-stimulating hormone (u-hFSH) have been introduced in an effort to reduce treatment burden by providing higher quality of treatment and, therefore, better quality of life. ${ }^{11-16}$ Evaluating women undergoing IVF from six clinics in Sweden between May 2010 and December 2010, Landfeldt et al found that patients were willing to pay several hundred euros to administer follicle-stimulating hormone (FSH) using a prefilled injection pen rather than a conventional syringe and for saving time during the application procedure. ${ }^{14}$ Furthermore, conducting a prospective survey on 123 patients over 1 year, Weiss found that $93.7 \%$ of patients preferred the use of a pen device vs a needle-free reconstitution and conventional syringe method. The most attractive feature of the prefilled pen was the ease of use, with a simple, reliable dosing mechanism and minimal perceived chance of error. ${ }^{13}$ These prefilled injection devices not only improve patient adherence but have become more frequently used in fertility treatment by health care practitioners who often have significant influence on patients' choice of administration method..$^{8,13,16}$ Weiss also found that comprehensive nurse-led training in the preparation and use of injectable FSH products enabled the majority of patients to select their preferred method of administration with confidence, with significant differences in preference between the different FSH devices. ${ }^{13}$

Despite the importance of FSH injection devices in improving treatment adherence, data are limited concerning product-specific features that drive both patient and healthcare practitioner preferences for these devices. In a market research study of a redesigned follitropin alfa pen injector for infertility, Abbotts et al found that the nurses preferred devices that could significantly reduce training time and simplify treatment protocol. ${ }^{8}$ However, only one pen injector and limited product features were assessed in this study, and answers about the tested device were primarily based upon recall. ${ }^{8}$ A study conducted by Schertz et al that assessed the usability testing of a redesigned follitropin alfa pen injector shared similar limitations. ${ }^{16}$ Therefore, in this study, we sought to assess a number of product-specific features across an array of self-administered injection devices and aimed to identify the key factor that patients and nurses in select European markets find most important when selecting specific injection devices for self-administration of $\mathrm{r}-\mathrm{hFSH} / \mathrm{u}-$ $\mathrm{hFSH}$ for fertility or reproductive treatment.

\section{Materials and methods Study participants}

This study was conducted among patients and nurses across eight European countries from May 2016 to June 2016. We surveyed 402 patients in the UK, Germany, France, Spain, Italy, the Netherlands, and Belgium, as well as 40 nurses working in reproduction/fertility spaces in Germany, Italy, France, Spain, and the Czech Republic. The sample size of patients and nurses surveyed in each individual country was proportional to their population.

Patients were eligible for study inclusion if they were females aged 18-45 years, had completed at least one IVF cycle or at least one ovarian stimulation, and had a mix of successful and unsuccessful ovarian stimulation, embryo implantation, and/or live birth. Male patients were excluded from the study. Survey responders who were not prescribed any FSH treatment in the past were also excluded from the study. Surveyed nurses included those who worked in either reproductive endocrinologist practices or infertility clinics and were familiar with, or had instructed, patients in the use of injectable ovarian stimulation treatment.

\section{Study design and methods}

Patient and nurse preferences for r-hFSH/u-hFSH selfadministered injection devices were obtained via an online 
questionnaire. Two quantitative analyses - the maximum differential scaling (MaxDiff) analysis, which ranks a large number of products at an individual level, and the conjoint analysis, which evaluates a smaller set of product attributes at a product level and determines specific qualities in overall product preference - were used to evaluate the survey results and derive the preferences of survey responders. In the MaxDiff survey, respondents were asked to select the most and least important attributes from a subset of product features. User preferences were then revealed through a direct comparison between the attributes. The result was a rank of attributes based upon the relative importance score to determine specific qualities in overall product preference. A total of 20 tested attributes were determined through the examination of the FSH injection devices that are currently available in the market (Table 1).

In the conjoint analysis, six product attributes of the 20 tested attributes from the MaxDiff survey were selected (Table 2). The selection of the attributes was based upon a review of 18 peer-reviewed journal articles published ${ }^{2-19}$ between 2006 and 2015 on patient and nurse preferences for $\mathrm{r}-\mathrm{hFSH} / \mathrm{u}-\mathrm{hFSH}$ injection devices. The attribute of "pen type" was separated from the attribute of "injection device" and was categorized into three detailed levels: single-use pen, multiple-use reusable pen, and multiple-use disposable pen. This categorization allowed more detailed learnings of user preference within attribute level. Comparing and evaluating product profiles that are constructed of individual attributes, the conjoint analysis simulates the real-world trade-off experience in decision-making process.

Respondents completed a questionnaire consisting of 10 conjoint analysis questions. Each question had two hypothetical products ( $\mathrm{A}$ and $\mathrm{B}$ ), each of which consisted of the tested attributes for responders to select (Table 3). The respondent was then asked to select one of the two hypothetical products that were built with selected attributes, assuming that both the products had the same cost, efficacy, and safety profile.

The study is a primary market research, conducted in accordance with European Society for Opinion and Marketing Research (ESOMAR) guidelines, that only solicited opinions from stakeholders with no actual clinical information collected. All product profiles shown in the survey form are hypothetical. No physical products are available. No personal information was collected, and no medical interventions were provided. All the surveys were conducted via the Internet with no physical interaction with the survey respondents. Participation was voluntary, and informed consent was taken by completion and return of the online survey. Therefore, this study did not go through an institutional review board for approval.

\section{Data analysis}

Survey data were cleaned and transferred to SAS version 9.2 (SAS Institute Inc., Cary, NC, USA). We derived descriptive and relative importance scores using a multinomial logit statistical modeling for both MaxDiff and conjoint analyses. The output of the model included mean coefficients representing the relative weights of each attribute conditional on other attributes. We converted these scores to ratio-scaled probabilities that range from 0 to 100 . The higher the score, the more important is the attribute or the stronger is the preference.

\section{Results \\ The characteristics of surveyed patients and nurses}

A total of 402 female patients from the UK ( $n=76)$, Germany $(n=94)$, France $(n=76)$, Spain ( $n=55)$, Italy $(n=69)$, the Netherlands ( $n=20)$, and Belgium $(n=12)$ completed the surveys. The baseline characteristics of the patient population are shown in Table 4 . The patients aged from 18 to 45 years (mean age: 34.25 years). Among 379 patients who previously completed IVF treatments, 207 (54.62\%) patients experienced a successful pregnancy, and 194 (51.19\%) patients had a healthy, live birth. Among 23 patients who previously followed a non-IVF procedure, 12 (52.17\%) patients experienced a successful pregnancy and all of them have had a healthy, live birth. Compared with the non-IVF procedure treatments, IVF treatments have resulted in more successful pregnancies but slightly fewer live births.

In addition, we surveyed 40 nurses who worked in relatively large reproductive endocrinologist practices or infertility clinics in France ( $\mathrm{n}=9)$, Germany $(\mathrm{n}=11)$, Italy $(n=9)$, Spain $(n=7)$, and the Czech Republic $(n=4)$; baseline characteristics are shown in Table 5. Nurses reported seeing an average of 299 patients per month.

\section{Results from the MaxDiff analysis}

The objective of using the MaxDiff analysis was to achieve relative importance scores for each attribute. A higher score deemed the attribute more important. The MaxDiff analysis indicated that the surveyed patients and nurses had preference discrepancies for product attributes.

According to the ranking scores (relative importance score [scale: 0-100]), patients ranked daily injection volume (8.91) and a desire for a pen injector (8.66) as the two most important factors when choosing a device, followed by an 
Table I The list of tested attributes and levels associated with each attribute

\begin{tabular}{|c|c|c|c|}
\hline ID & Attributes & Levels & Description \\
\hline I & Injection device & $\begin{array}{l}\text { - Single-use pen } \\
\text { - Multiple-use pen, reusable } \\
\text { - Multiple-use pen, disposable } \\
\text { - Syringe and vials; or prefilled syringes }\end{array}$ & Type of injector used for administering the drug \\
\hline 2 & $\begin{array}{l}\text { With "Steady Grip" } \\
\text { feature }\end{array}$ & $\begin{array}{l}\text { - Yes } \\
\text { - No }\end{array}$ & Grip that helps the user to stably hold the pen injector \\
\hline 3 & $\begin{array}{l}\text { Visibility of remaining } \\
\text { product in cartridge }\end{array}$ & $\begin{array}{l}\text { - Yes } \\
\text { - No }\end{array}$ & User can see the level of leftover drug in the loaded cartridge \\
\hline 4 & $\begin{array}{l}\text { Number of needles in } \\
\text { the package }\end{array}$ & Range from 5 to 14 & The number of replacement needles in the package \\
\hline 5 & With large display & $\begin{array}{l}\text { - Yes } \\
\text { - No }\end{array}$ & A large display window for the amount of drug to be injected \\
\hline 6 & Dosing accuracy & $\begin{array}{l}\text { Percentage of errors } \\
\text { (range from } 1 \% \text { to } 3 \% \text { ) }\end{array}$ & $\begin{array}{l}\text { Variation per day measured as percentage of the total daily } \\
\text { injection amount }\end{array}$ \\
\hline 7 & Minimum dosing & Range from $8.33 \mathrm{IU}$ to $\mathrm{I} 50 \mathrm{IU}$ & Smallest amount of drug that can be injected using the device \\
\hline 8 & Unit display & $\begin{array}{l}\text { - Dash } \\
\text { - Numerical }\end{array}$ & $\begin{array}{l}\text { This attribute describes how the injection amount can be read } \\
\text { from the device. } \\
\text { Dash: }\end{array}$ \\
\hline 9 & Dial back function & $\begin{array}{l}\text { - Yes } \\
\text { - No }\end{array}$ & $\begin{array}{l}\text { Dose correction can be made by turning the dial backwards to } \\
\text { set a lower dose }\end{array}$ \\
\hline 10 & Daily injection volume & $\begin{array}{l}\text { - } 0.01,0.1,0.3 \mathrm{~mL} \text { for pens } \\
\text { - } \mathrm{I}-2 \mathrm{~mL} \text { for syringes }\end{array}$ & Total volume of liquid being injected \\
\hline II & Operation & $\begin{array}{l}\text { - Side button (semi-automatic) } \\
\text { - Push plunge (manual) }\end{array}$ & $\begin{array}{l}\text { The mechanism by which the injection is being performed } \\
\text { - Push plunge requires user to push the plunger down as far as } \\
\text { possible to deliver the medicine } \\
\text { - The side button mechanism is semiautomatic: the injection is } \\
\text { completed automatically following a single button press }\end{array}$ \\
\hline 12 & $\begin{array}{l}\text { Has overfilled cartridge } \\
\text { for device priming }\end{array}$ & $\begin{array}{l}\text { - Yes } \\
\text { - No }\end{array}$ & $\begin{array}{l}\text { Overfilled cartridge provides additional medicine for injector } \\
\text { preparation }\end{array}$ \\
\hline 13 & $\begin{array}{l}\text { Able to use multiple } \\
\text { cartridges for one } \\
\text { injection }\end{array}$ & $\begin{array}{l}\text { - Yes } \\
\text { - No }\end{array}$ & $\begin{array}{l}\text { Multiple cartridges can be combined in pen to supply sufficient } \\
\text { medicine to complete the required dose in a single injection }\end{array}$ \\
\hline 14 & Dosing increment & $\begin{array}{l}\text { I2.5- } 25 \text { IU for pens } \\
\text { (should not exceed I } 50 \text { IU per adjustment } \\
\text { for syringes) }\end{array}$ & Smallest incremental value for which the injection can be adjusted \\
\hline 15 & Treatment diary & $\begin{array}{l}\text { - Yes } \\
\text { - No }\end{array}$ & Allows the user to track their injection activities \\
\hline 16 & Product wastage & $\begin{array}{l}\text { - High } \\
\text { - Low }\end{array}$ & $\begin{array}{l}\text { Medicine wasted due to dosing change. } \\
\text { - Low wastage: }<50 \mathrm{IU} \\
\text { - High wastage: }>100 \mathrm{IU}\end{array}$ \\
\hline 17 & Easy for nurse to teach & $\begin{array}{l}\text { - Yes } \\
\text { - No }\end{array}$ & $\begin{array}{l}\text { This is a general assessment about how easy it is to teach a } \\
\text { patient to use the device for self-injection }\end{array}$ \\
\hline 18 & $\begin{array}{l}\text { Time to remove from } \\
\text { refrigerator before use }\end{array}$ & $\begin{array}{l}\text { - } 10 \text { minutes } \\
\text { - } 30 \text { minutes }\end{array}$ & $\begin{array}{l}\text { Time required between the medicine being removed from the } \\
\text { refrigerator and administration }\end{array}$ \\
\hline 19 & Needle size & Range from 27 to 30 gage & Size of needle, where larger number indicates a smaller needle \\
\hline 20 & Carrying pouch size & $\begin{array}{l}\text { - Standard } \\
\text { - Small }\end{array}$ & $\begin{array}{l}\text { Size of the container for the injection product bundle: } \\
\text { - Standard refers to a dimension of } 23 \mathrm{~cm}\left(9.10^{\prime \prime}\right) \times 1 \mathrm{I} \mathrm{cm} \\
\left(4.33^{\prime \prime}\right) \times 5 \mathrm{~cm}(1.97 ") \\
\text { - Small size is half the standard size }\end{array}$ \\
\hline
\end{tabular}


Table 2 The list of tested attributes and levels associated with each attribute

\begin{tabular}{|c|c|c|c|}
\hline ID & Attributes & Levels & Description \\
\hline I & Injection device & $\begin{array}{l}\text { - Pen } \\
\text { - Syringe and vials ( }(-2 \mathrm{~mL})\end{array}$ & Type of injector used for administering the drug \\
\hline 2 & Pen type & $\begin{array}{l}\text { - Single-use pen } \\
\text { - Multiple-use pen, reusable } \\
\text { - Multiple-use pen, disposable }\end{array}$ & Type of pen used for administration \\
\hline 3 & $\begin{array}{l}\text { Visibility of remaining product in } \\
\text { cartridge }\end{array}$ & $\begin{array}{l}\text { - Yes } \\
\text { - No }\end{array}$ & User can see the level of leftover drug in the loaded cartridge \\
\hline 4 & Daily injection volume & $\begin{array}{l}\text { - } 0.01,0.1,0.3 \mathrm{~mL} \text { for pens } \\
\text { - } \mathrm{I}-2 \mathrm{~mL} \text { for syringes }\end{array}$ & Total volume of liquid being injected \\
\hline 5 & Product wastage & $\begin{array}{l}\text { - High } \\
\text { - Low }\end{array}$ & $\begin{array}{l}\text { Medicine wasted due to dosing change: } \\
\text { - Low wastage: }<50 \mathrm{IU} \\
\text { - High wastage: }>100 \mathrm{IU}\end{array}$ \\
\hline 6 & Easy for nurse to teach & $\begin{array}{l}\text { - Yes } \\
\text { - No }\end{array}$ & $\begin{array}{l}\text { General assessment of how easy it is to teach a patient to use } \\
\text { the device for self-injection }\end{array}$ \\
\hline
\end{tabular}

injector with a dial-back function (6.78), low incremental dosing (6.22), and ability to reuse multiple cartridges (5.61). The five attributes that patients found least important were product wastage (3.33), the feature of having a large display window (3.26), treatment diary (3.06), unit display (3.06), and the number of needles in the package (2.85; Figure 1).

Compared to the surveyed patients, nurses had different preferences for product attributes. Survey data (relative importance score [scale: $0-100$ ]) indicated that nurses placed greater value on features related to patient management, including dosing accuracy (16.82), a dial-back function (13.09), ease of teaching the patients (12.27), and a visibility feature (11.14) that would enable patients to estimate residual cartridge content. Nurses were less driven by convenience factors, including needle size (1.56), number of needles in the package ( 0.88$)$, carrying pouch size (0.44), and treatment diary ( 0.38 ; Figure 2$)$.

\section{Results from the conjoint analysis}

Compared to the MaxDiff analysis, the conjoint analysis provides a clearer picture of respondent preferences for the key attributes. As shown in Figure 3, the type of injection device (pen vs syringe) served as the greatest point of influence on patient selection of preferred r-hFSH/u-hFSH selfadministered products (relative importance score $=67.64 \%$ ). Patients ranked dosing accuracy (relative importance score [scale: $0 \%-100 \%$ ]) as the second most important factor in choosing a device (12.60\%), followed by pen type (10.05\%), daily injection volume (4.95\%), a visibility feature $(4.61 \%)$, and product wastage $(0.15 \%)$.

Like patients, "injection device" predominantly impacted nurses' choice of FSH self-administration products (relative importance score $=53.22 \%$, Figure 4 ). Additional attributes (ranked using relative importance score) considered important to nurses were features related to patient management, including ease of teaching patients $(21.63 \%)$ and the visibility feature (13.48\%). Nurses were less driven by convenience factors, including pen type (6.67\%) and daily injection volume (1.24\%). Dosing accuracy was also found to be less important $(3.76 \%)$ in impacting nurses' choice for a selfadministered FSH product vs patients' choice (Figure 4).

Table 3 Example of conjoint analysis question

\begin{tabular}{|l|l|}
\hline Hypothetical product A & Hypothetical product B \\
\hline It is provided in an injection pen & $\begin{array}{l}\text { It is provided in either a prefilled syringe or a syringe that needs to be } \\
\text { filled prior to injection }\end{array}$ \\
\hline $\begin{array}{l}\text { The pen can be used for multiple injections as long as the reservoir is } \\
\text { not depleted. The pen is also disposable }\end{array}$ & The pen can be used for a single injection only and is non-reusable \\
\hline $\begin{array}{l}\text { The remaining drug in a loaded cartridge cannot be seen through a } \\
\text { window on the pen }\end{array}$ & $\begin{array}{l}\text { The remaining drug in a loaded cartridge cannot be seen through a } \\
\text { window on the pen }\end{array}$ \\
\hline $\begin{array}{l}\text { On average, this product will have an injection error within I.5\% of the } \\
\text { patient's prescribed daily dosage }\end{array}$ & $\begin{array}{l}\text { On average, this product will have an injection error within } 3.0 \% \text { of the } \\
\text { patient's prescribed daily dosage }\end{array}$ \\
\hline The daily injection volume using product A is $0.3 \mathrm{~mL}$ & The daily injection volume using product B is $0.0 \mathrm{I} \mathrm{mL}$ \\
\hline The product wastage is more than I00 IU & The product wastage is less than $50 \mathrm{IU}$ \\
\hline
\end{tabular}


Table 4 Baseline characteristics of female patients participating in the survey

\begin{tabular}{|l|l|l|l|l|l|l|l|}
\hline & UK & Germany & France & Italy & Spain & $\begin{array}{l}\text { The } \\
\text { Netherlands }\end{array}$ & Belgium \\
\hline Patients, $n$ & 76 & 94 & 76 & 69 & 55 & 20 & 12 \\
\hline Mean age, years & 33.30 & 35.5 I & 33.64 & 35.42 & 33.56 & 31.58 & 31.5 \\
\hline $\begin{array}{l}\text { Previously on IVF } \\
\text { treatments, n (\%) }\end{array}$ & $75(98.68)$ & $89(94.68)$ & $74(93.37)$ & $63(91.30)$ & $50(90.90)$ & $18(90.00)$ & $10(83.33)$ \\
\hline $\begin{array}{l}\text { Previously on non-IVF } \\
\text { treatments, n (\%) }\end{array}$ & I (I.32) & $5(5.32)$ & $2(2.63)$ & $6(1.50)$ & $5(9.10)$ & $2(10.00)$ & $2(16.67)$ \\
\hline Pregnancy with IVF (\%) & 57.33 & 56.18 & 60.81 & 44.44 & 58.00 & 44.44 & 40.00 \\
\hline Live birth with IVF (\%) & 57.33 & 49.44 & 56.76 & 42.86 & 52.00 & 44.44 & 40.00 \\
\hline
\end{tabular}

Abbreviation: IVF, in vitro fertilization.

In addition, a series of scenario analyses were conducted to better identify the importance of product attributes to influence patients' choices. Assuming that only one attribute was changed at one time, with all other factors being equal, we found that the results were aligned with the preference rankings provided in Figures 3 and 4. For instance, assuming dosing accuracy and product wastage were the same for two products (as displayed in Table 6), 63\% of patient respondents preferred product $\mathrm{A}$ to product $\mathrm{B}$, indicating the preference for a pen device over a conventional syringe. Also, assuming that product $\mathrm{A}$ is a multiple-use pen and product $\mathrm{B}$ is a single-use pen, with all other factors remaining the same (as displayed in Table 7), we found that $>50 \%$ of the patient respondents preferred product A to product B, indicating a slightly greater preference for a multiple-use pen vs a single-use pen.

\section{Differences between countries}

Conjoint analysis by individual country suggested that patients from all surveyed countries, apart from Belgium,

Table 5 Baseline characteristics of nurses participating in survey

\begin{tabular}{|l|l|}
\hline $\begin{array}{l}\text { Total number of nurses who have completed the surveys } \\
\text { Total number of nurses who work in reproductive } \\
\text { endocrinologist practice }\end{array}$ & \begin{tabular}{l}
40 \\
\hline Total number of nurses who work in infertility clinics
\end{tabular} \\
\hline $\begin{array}{l}\text { Average number of physicians at the practice where the } \\
\text { nurse works }\end{array}$ & 37 \\
\hline $\begin{array}{l}\text { Average number of nurses at the practice where the nurse } \\
\text { works }\end{array}$ & 6 \\
\hline Average number of patients that the nurse sees monthly & 299 \\
\hline $\begin{array}{l}\text { Percentage of patients that these nurses see who are using } \\
\text { self-administered injectable ovarian stimulation treatments }\end{array}$ & 69 \\
\hline $\begin{array}{l}\text { Percentage of patients who are using self-administered } \\
\text { ovarian stimulation treatments via injection pens }\end{array}$ & 67 \\
\hline $\begin{array}{l}\text { The average number of years of infertility treatment } \\
\text { experience }\end{array}$ & 9 \\
\hline
\end{tabular}

shared similar views of the relative importance of certain FSH injection device attributes (Figure 5). Results showed that patients from Belgium found the six selected attributes equally important in terms of influencing their choice for r-hFSH/u-hFSH products. Compared with respondents from other countries, the Belgian survey responders were very young, with approximately one-half of surveyed patients aged 18-25 years. These respondents were also less experienced in IVF treatment; only four patients had experienced a successful pregnancy.

Conjoint analysis by individual country suggested that nurse preferences for the selected attributes varied greatly between countries (Figure 6). Nurses from Germany and France indicated that the type of injection device (eg, pen vs syringe) dominated all other product attributes. Nurses from Spain and Italy, however, felt that, in addition to injection device, "ease to teach" and a visibility feature were also important. For the nurses from the Czech Republic, attributes of "ease to teach" and "visibility to leftover product in cartridge" were both important.

\section{Discussion}

Surveying 402 patients from seven European countries and 40 nurses from five European countries, we identified a series of product features that may influence patient and nurse preferences relative to the selection of an injection device for the self-administration of fertility treatment in select European markets. Importantly, our findings indicate that both shared and discrepant preferences of patients and nurses for features of FSH injection devices reflect their individual perspectives. For patients and nurses, the ideal FSH injection device would be a highly accurate, multi-use pen injector, with a dial-back function that is easy to use and/or teach.

Categorically, patients value factors that result in minimal impact on daily life (including reduced injection volume to reduce injection-site pain as well as a reusable device which 


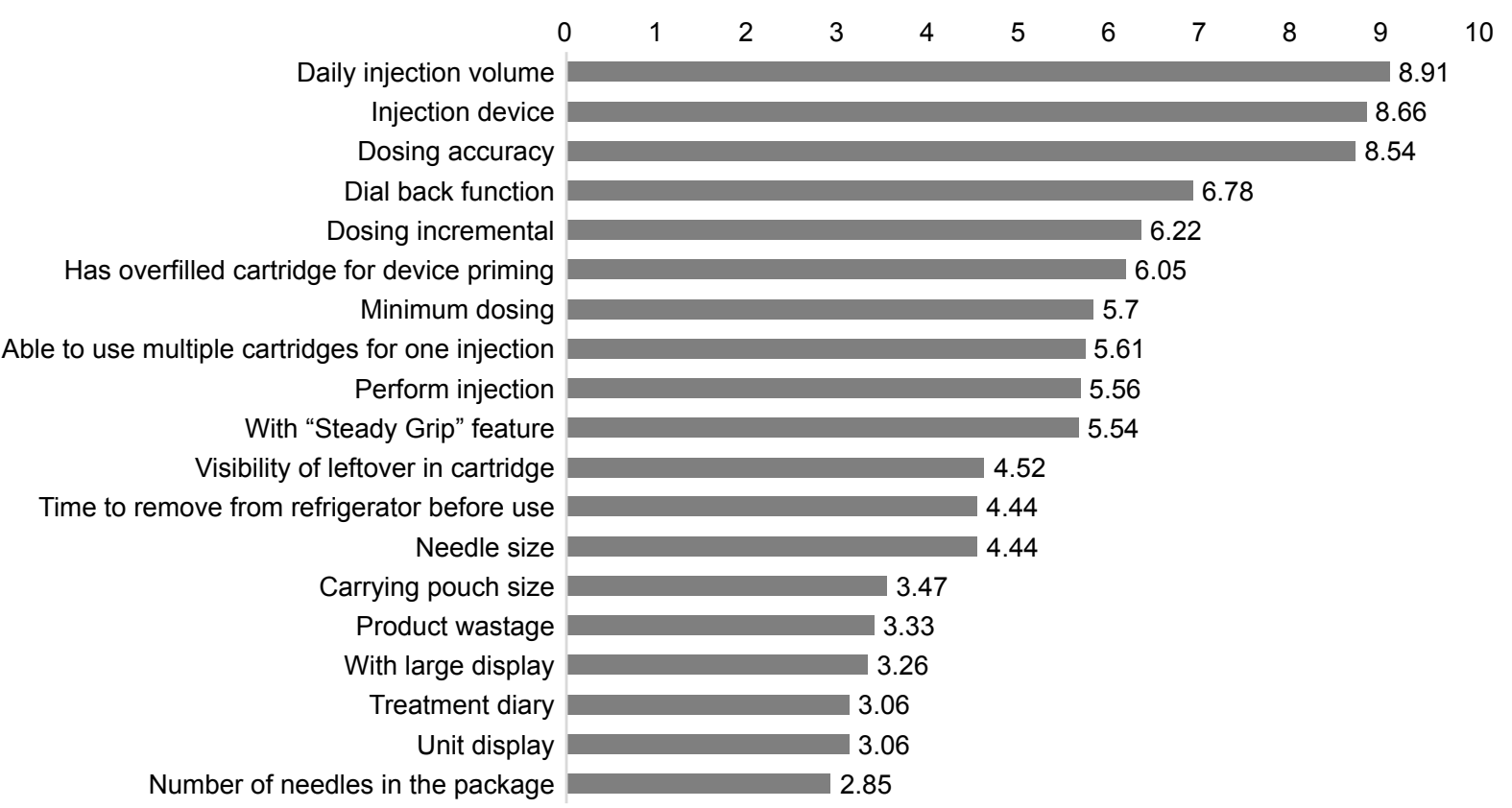

Figure I Patient preference ranking of the tested attributes from the MaxDiff analysis.

Abbreviation: MaxDiff, maximum differential scaling.

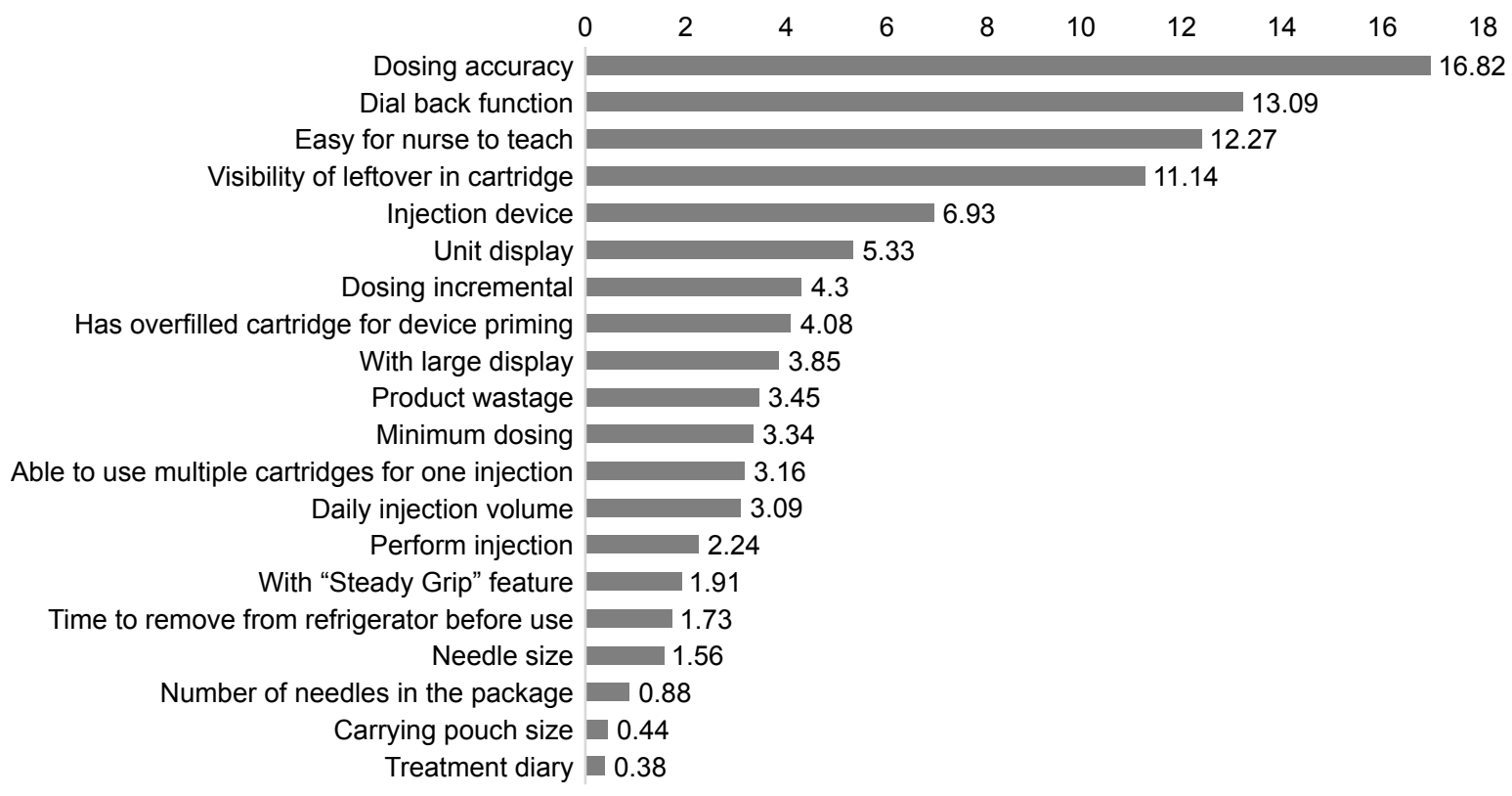

Figure 2 Nurse preference ranking of the tested attributes from the MaxDiff analysis.

Abbreviation: MaxDiff, maximum differential scaling.

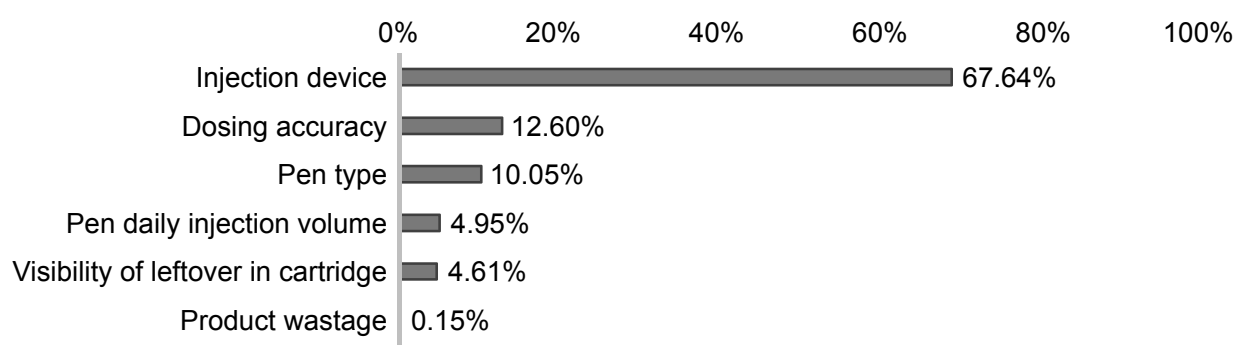

Figure 3 Patient preference ranking of selected attributes from the conjoint analysis. 


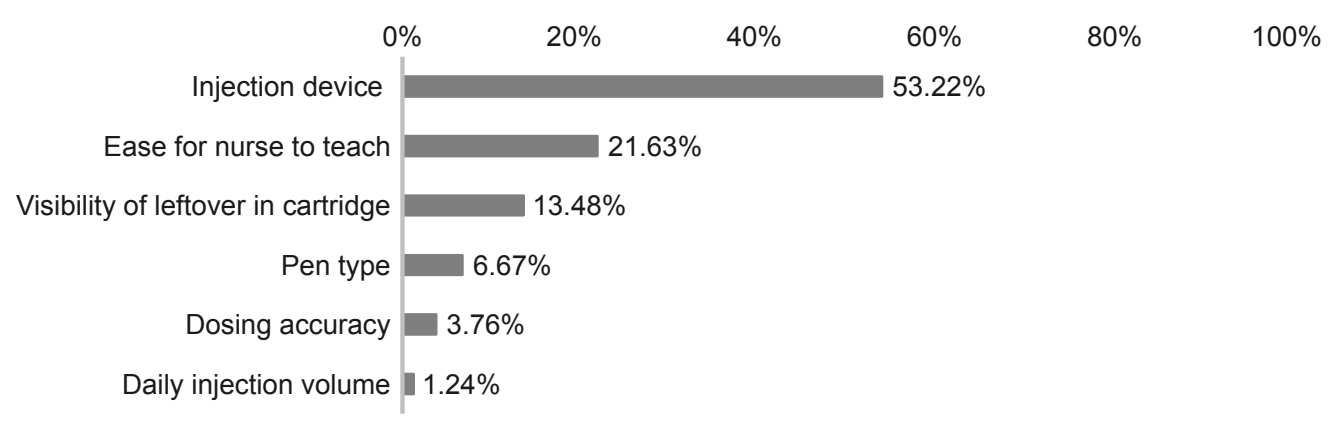

Figure 4 Nurse preference ranking for the selected attributes from the conjoint analysis.

is easy to use), while nurses value ease of teaching in order to instruct the greatest number of patients while minimizing risk. Our results indicate that, with respect to reproductive/ fertility treatment, patients care greatly about product attributes associated with the quality of care, while nurses place greater value on protocols and technical attributes. The lack of importance of daily injection volume indicated by nurses compared with patients is most likely reflective of the relative impact injection volume has on the experience of that stakeholder. That is, injection volume will exhibit a minimal impact on a nurse's ability to provide appropriate treatment; however, as it is associated with significant injection-site pain, it may have an adverse impact on patient quality of life.

Our findings also suggest that, apart from Belgian and Dutch patients, product wastage is a nondetermining factor for the patients surveyed across the selected European markets. This may be attributed to patients not realizing the relationship between increases in the overall cost of treatment and, thus, out-of-pocket patient expenses as a result of product wastage. This may also be due to higher environmental awareness in these countries.

Data from the overall survey support the conclusion that patients perceived similar needs for FSH injection device

Table 6 The attribute characteristics of two hypothetical products in scenario analysis I

\begin{tabular}{|l|l|l|l|}
\hline & & Product A & Product B \\
\hline I & Injection device & Pen & $\begin{array}{l}\text { Syringe and vial } \\
(\mathrm{I}-2 \mathrm{~mL})\end{array}$ \\
\hline 2 & Pen type & Single-use pen & \\
\hline 3 & $\begin{array}{l}\text { Visibility of } \\
\text { leftover product }\end{array}$ & No & \\
\hline 4 & Dosing accuracy & $3 \%$ error & $3 \%$ error \\
\hline 5 & $\begin{array}{l}\text { Pen daily injection } \\
\text { volume }\end{array}$ & $0.3 \mathrm{~mL}$ & \\
\hline 6 & Product wastage & High & High \\
\hline
\end{tabular}

design at the country-specific level, focusing on factors that affect daily living as well as accurate treatment. Countryspecific differences exist in overall order of product characteristics; however, most important features typically remain constant.

This study encompassed characteristics of all FSH devices on the market without reference to any brands in the survey, and our results showed a variability in the features preferred by patients and nurses, most of which are present in the Ovaleap ${ }^{\circledR}$ Pen. The selected preferred attributes for available FSH treatments are listed in Table 8. The corresponding attributes that were considered favorable to patients and nurses are highlighted.

To the best of our knowledge, there are currently no studies that holistically evaluate the product attributes selected in this study using both MaxDiff and conjoint analyses. For instance, evaluating women undergoing IVF from six clinics in Sweden between May 2010 and December 2010, Landfeldt et al employed a conjoint analysis and tested five hypothetical product attributes. ${ }^{14}$ They found that dosing accuracy and reduced variability were the most important characteristics sought by patients who were even ready to pay a substantial amount of money to reduce the dose variability. ${ }^{14}$ This echoes our findings that dosing

Table 7 The attribute characteristics of two hypothetical products in scenario analysis 2

\begin{tabular}{|l|l|l|l|}
\hline & & Product A & Product B \\
\hline $\mathbf{I}$ & Injection device & Pen & Pen \\
\hline 2 & Pen type & $\begin{array}{l}\text { Multiple-use } \\
\text { reusable pen }\end{array}$ & Single-use pen \\
\hline 3 & $\begin{array}{l}\text { Visibility of leftover } \\
\text { in cartridge }\end{array}$ & No & No \\
\hline 4 & Dosing accuracy & $3 \%$ error & $3 \%$ error \\
\hline 5 & $\begin{array}{l}\text { Pen daily injection } \\
\text { volume }\end{array}$ & $0.3 \mathrm{~mL}$ & $0.3 \mathrm{~mL}$ \\
\hline 6 & Product wastage & High & High \\
\hline
\end{tabular}




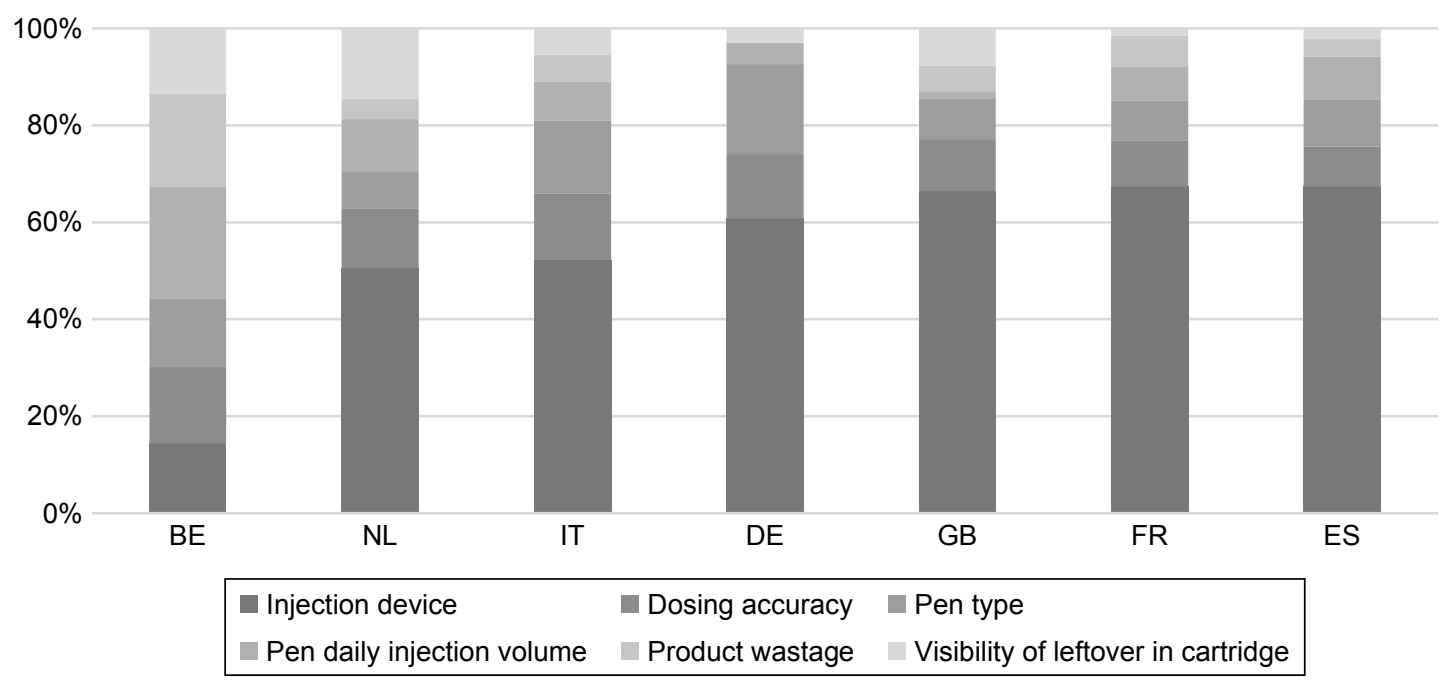

Figure 5 The country-wise comparison of the relative importance score of attributes among patients. Abbreviations: BE, Belgium; NL, the Netherlands; IT, Italy; FR, France.

accuracy is the feature that patients care about most. Using a conjoint analysis, Palumbo et al also evaluated female Spanish patients' preferences of five product attributes, including price. ${ }^{17}$ In a discrete choice experiment, van den Wijngaard et al assessed patient preference for long-acting or daily-administered r-hFSH under only three attributes: efficiency, safety, and burden. ${ }^{11}$ Therefore, the present study may provide some unique insights on patient and nurse preferences for $\mathrm{r}-\mathrm{hFSH} / \mathrm{u}-\mathrm{hFSH}$ injection devices and fill the current literature gap on this topic.

\section{Limitations}

One limitation of this study was the sample size. The sample of surveyed patients and nurses was sufficient for a pooled data analysis at the larger European/continental level. However, it may not be adequate for stratified analysis of certain individual countries. For instance, only 12 Belgian patients participated in the online surveys, which may lead to a potential issue of generalizability when investigating Belgium separately. An additional study with a larger sample size to compare different treatment products is warranted. Another limitation is related to the study design. Both patient and nurse surveys comprised 19 similar MaxDiff questions, which may have led to the issue of survey fatigue. As such, respondents may answer questions using copy strategies. In this study, we found that 14 patient respondents never changed their answers across all questions.

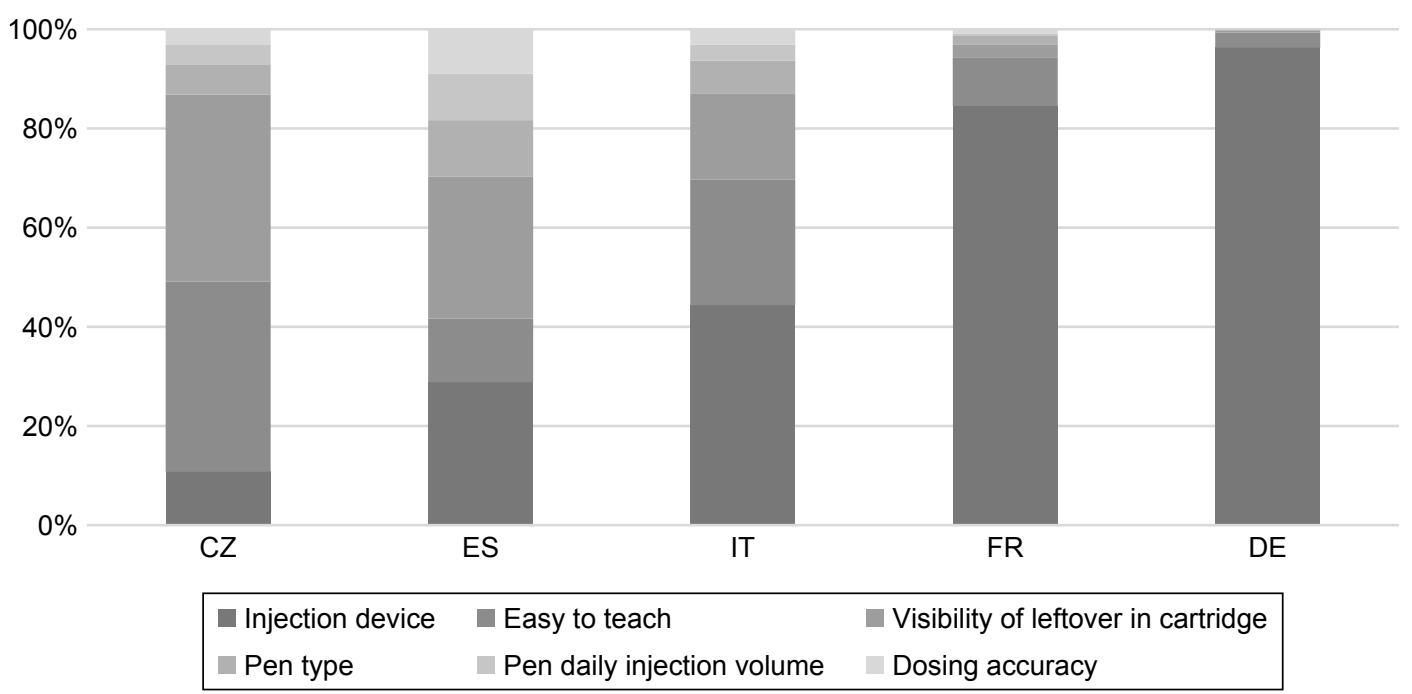

Figure $\mathbf{6}$ The country-wise comparison of the relative importance score of attributes among nurses. Abbreviations: CZ, Czech Republic; IT, Italy; FR, France. 
Table 8 Selected preferred product attributes of currently available FSH injection devices

\begin{tabular}{|l|l|l|l|l|l|l|l|}
\hline & Attributes & Gonal-f $^{\circledR}$ & Puregon $^{\circledR}$ & Bemfola $^{\circledR}$ & Ovaleap $^{\circledR}$ & Bravelle $^{\circledR}$ & Menopur $^{\circledR}$ \\
\hline I & $\begin{array}{l}\text { Daily injection } \\
\text { volume (I50 IU) }\end{array}$ & $0.25 \mathrm{~mL}$ & $0.18 \mathrm{~mL}$ & $0.25 \mathrm{~mL}$ & $0.25 \mathrm{~mL}$ & $\mathrm{I}-2 \mathrm{~mL}$ & $\mathrm{I}-2 \mathrm{~mL}$ \\
\hline 2 & Injection device & $\begin{array}{l}\text { Single-use, } \\
\text { multidose, pen }\end{array}$ & $\begin{array}{l}\text { Multi-use, } \\
\text { multidose, pen }\end{array}$ & $\begin{array}{l}\text { Single-use, } \\
\text { single-dose, pen }\end{array}$ & $\begin{array}{l}\text { Multi-use, } \\
\text { multidose, pen }\end{array}$ & Syringe and vials & Syringe and vials \\
\hline 3 & Dial-back function & Yes & No & Yes & Yes & - & - \\
\hline 4 & Dosing increments & I2.5 IU & $25 \mathrm{IU}$ & $12.5 \mathrm{IU}$ & I2.5 IU & - & - \\
\hline 5 & Perform injection & Push knob & Push knob & Plunger & Release button & & \\
\hline 6 & $\begin{array}{l}\text { Visibility of leftover } \\
\text { in cartridge }\end{array}$ & Yes & No & NA & Yes & & \\
\hline
\end{tabular}

\section{Conclusion}

Although patients value factors that result in minimal impact on daily life when choosing self-administered FSH injection devices and nurses value ease of teaching in order to instruct the greatest number of patients while minimizing risk, patient and nurse preferences were generally aligned. Overall, the preferred attributes identified - an easy-to-use, multi-use reusable pen injector, with a dial back function and a visibility feature - were all characteristics of the Ovaleap ${ }^{\circledR}$ Pen.

\section{Disclosure}

This study was supported by Teva Pharmaceutical Industries. Teva provided a full review of the manuscript. P Zitoun received honoraria from Ferring and Teva. P Zitoun worked at the Clinique Pierre Cherest during the study and now works at American Hospital of Paris. J Parikh is a fertility consultant at Lister Fertility Clinic, London, UK. M Nijs is a lecturer at Origio, a Cooper Surgical Company. W Zhang is an employee of WG Consulting, whose work on this project was funded by Teva Global Health Economics \& Outcomes Research. R Levy-Toledano was a consultant for Teva Europe Medical Affairs during the study and currently a consultant as Fertility Medical Director for Theramex HQ UK Limited. B Tang was Teva employee during the study. The authors report no other conflicts of interest in this work.

\section{References}

1. ESHRE Capri Workshop Group. Europe the continent with the lowest fertility. Hum Reprod Update. 2010;16(6):590-602.

2. Aghssa MM, Azargoon A, Ramezanzadeh F, Bagheri M. A comparison of the efficacy, tolerability, and convenience of two formulations of follitropin-alpha in Iranian woman undergoing intracytoplasmic sperm injection cycles. Fertil Steril. 2008;90(4):1043-1048.

3. Domar A, Gordon K, Garcia-Velasco J, La Marca A, Barriere P, Beligotti F. Understanding the perceptions of and emotional barriers to infertility treatment: a survey in four European countries. Hum Reprod. 2012;27(4):1073-1079.
4. Boivin J, Domar AD, Shapiro DB, Wischmann TH, Fauser BC, Verhaak C. Tackling burden in ART: an integrated approach for medical staff. Hum Reprod. 2012;27(4):941-950.

5. Porter R, Kissel C, Saunders H, Keck C. Patient and nurse evaluation of recombinant human follicle-stimulating hormone administration methods: comparison of two follitropin injection pens. Curr Med Res Opin. 2008;24(3): 727-735.

6. Hovatta O, McVeigh E, Lass A, Homburg R, Northern Europe Gonal-f Pre-Filled Pen PMS Group. A large Northern European observational study of follitropin alpha filled-by-mass pre-filled pen. Reprod Biomed Online. 2009; 18(4):502-508.

7. Welcker JT, Nawroth F, Bilger W. Patient evaluation of the use of follitropin alfa in a prefilled ready-to-use injection pen in assisted reproductive technology: an observational study. Reprod Biol Endocrinol. 2010;8(1):111.

8. Abbotts C, Salgado-Braga C, Audibert-Gros C. A redesigned follitropin alfa pen injector for infertility: results of a market research study. Patient Prefer Adherence. 2011;5:315-331.

9. Utsunomiya T, Tanaka A, Tatsumi K, Ezcurra D. A questionnaire-based survey to assess patient satisfaction, ease-of-learning, ease-of-use, injection site pain and overall patient satisfaction of the follitropin-alpha (Gonal-f) filled-by-mass (FbM) prefilled pen compared with other systems of gonadotrophin administration. Reprod Biol Endocrinol. 2012;10(1):93.

10. Illingworth PJ, Lahoud R, Quinn F, Chidwick K, Wilkinson C, Sacks G. Single-arm, observational study of the ease of use of a redesigned pen device to deliver recombinant human follicle-stimulating hormone (follitropin alfa) for assisted reproductive technology treatment. Patient Prefer Adherence. 2014;8:813.

11. van den Wijngaard L, Rodijk IC, van der Veen F, et al. Patient preference for a long-acting recombinant FSH product in ovarian hyperstimulation in IVF: a discrete choice experiment. Hum Reprod. 2015;30(2): 331-337.

12. Sedbon E, Wainer R, Perves C. Quality of life of patients undergoing ovarian stimulation with injectable drugs in relation to medical practice in France. Reprod Biomed Online. 2006;12(3):298-303.

13. Weiss N. Gonadotrophin products: empowering patients to choose the product that meets their needs. Reprod Biomed Online. 2007; 15(1):31-37.

14. Landfeldt E, Jablonowska B, Norlander E, et al. Patient preferences for characteristics differentiating ovarian stimulation treatments. Hum Reprod. 2012;27(3):760-769.

15. Bühler K. Managing infertility with the follitropin alfa prefilled pen injector - patient considerations. Ther Clin Risk Manag. 2015; 11:995.

16. Schertz JC, Saunders H, Hecker C, Lang B, Arriagada P. The redesigned follitropin alfa pen injector: results of the patient and nurse human factors usability testing. Expert Opin Drug Deliv. 2011;8(9):1111-1120. 
17. Palumbo A, de La Fuente P, Rodríguez M, et al. Willingness to pay and conjoint analysis to determine women's preferences for ovarian stimulating hormones in the treatment of infertility in Spain. Hum Reprod. 2011;26(7):1790-1798.

18. Patil M. Gonadotrophins: the future. J Hum Reprod Sci. 2014;7(4): 236-248.
19. Saunders H, Schertz JC, Hecker C, Lang B, Arriagada P. The recombinant human chorionic gonadotropin prefilled pen: results of patient and nurse human factors usability testing. Expert Opin Drug Deliv. 2012;9(8):893-900.

\section{Publish your work in this journal}

The International Journal of Women's Health is an international, peerreviewed open-access journal publishing original research, reports, editorials, reviews and commentaries on all aspects of women's healthcare including gynecology, obstetrics, and breast cancer. The manuscript management system is completely online and includes a very quick and fair peer-review system, which is all easy to use. Visit http://www.dovepress.com/testimonials.php to read real quotes from published authors.

Submit your manuscript here: http://www.dovepress.com/international-journal-of-womens-health-journal 